\title{
SÉBASTIEN RONGIER, Duchamp et le cinéma, Valréas
}

\section{Marcella Biserni}

\section{CpenEdition}

\section{Journals}

\section{Edizione digitale}

URL: https://journals.openedition.org/studifrancesi/23057

DOI: 10.4000/studifrancesi.23057

ISSN: 2427-5856

\section{Editore}

Rosenberg \& Sellier

\section{Edizione cartacea}

Data di pubblicazione: 1 avril 2020

Paginazione: 212-213

ISSN: 0039-2944

\section{Notizia bibliografica digitale}

Marcella Biserni, «SÉBAStien Rongier, Duchamp et le cinéma, Valréas», Studi Francesi [Online], 190 (LXIV I

I) | 2020, online dal 01 mai 2020, consultato il 03 août 2021. URL: http://journals.openedition.org/ studifrancesi/23057 ; DOI: https://doi.org/10.4000/studifrancesi.23057

\section{Questo documento è stato generato automaticamente il 3 août 2021}

\section{(c) (†)}

Studi Francesi è distribuita con Licenza Creative Commons Attribuzione - Non commerciale - Non opere derivate 4.0 Internazionale. 


\title{
SÉBASTIEN RONGIER, Duchamp et le cinéma, Valréas
}

\author{
Marcella Biserni
}

\section{NOTIZIA}

SÉBASTIEN RONGIER, Duchamp et le cinéma, Valréas, Nouvelles éditions Place, 2018, 121

pp.

1 Il testo di S. Rongier fa parte di una collana dedicata al rapporto tra scrittura o arte e cinema. Tra i vari autori e artisti presi in considerazione, troviamo qui Marcel Duchamp, il cui rapporto con la pellicola inizia fin dall'epoca della sua "militanza" nel gruppo dadaista. Dai suoi esordi, Duchamp esprime infatti l'urgenza di un adeguamento all'evolversi dell'arte e dei modi di rappresentazione del reale. Questo è anche il punto di partenza dell'analisi di Rongier, che già nell'introduzione pone la questione della meccanizzazione della pittura come input quasi imprescindibile alle creazioni dell'artista. Il testo si divide in tre capitoli e vari sottocapitoli: l'attenzione si focalizza sulla figura di Duchamp come attore e cineasta, sull'essenza ironica ed erotica della sua trasformazione attraverso lo pseudonimo Rrose Sélavy ed infine sulla sua eredità cinematografica.

Il passaggio da una pratica a un'altra sembra essere l'unica via d'uscita. Duchamp coglie la sfida mescolando testo e immagine oltre all'arte figurativa. Infatti, le sue sperimentazioni toccano anche il cinema e da più angolazioni: sia da attore che da regista. In «Marcel Duchamp, acteur et cinéaste» l'autore analizza la meccanica dell'atto creativo duchampiano, attorno alla figura del cerchio: a partire dai disegni preparatori per il Grand verre fino ai dischi ottici Rotoreliefs e ad Anémic cinéma. La questione dei ronds crea un fil rouge nell'intero arco della vita artistica dell'artista, sebbene nelle sue numerose collaborazioni si ritrovino altri temi ricorrenti, come gli scacchi o i travestimenti. Duchamp opera con metodo scientifico, ma al contempo ironizza sulla realtà, creando mere illusioni ottiche. Così, il trompe-l'œil visivo si 
intreccia al testo in un gioco di parole che gira nelle sue ruote all'infinito, ammiccando all'arte di girare/tourner dei film.

3 Nel secondo capitolo, «Rrose Sélavy, cinéaste de la famille», l'autore collega aneddoti personali dell'artista alle opere, spesso combacianti con il ricercato rovesciamento del maschile e del femminile, ormai intercambiabili. La nascita di Rrose ridefinisce l'identità sessuale, creando un ibrido che è specchio del mescolamento delle arti, in quanto tutto è rimesso in discussione, assieme al ruolo dell'artista. Duchamp proprio nel cinema si traveste in Rrose, a rimarcare la sovversione dei generi e una maggiore libertà di esplorazione dello spazio tra gli elementi, ossia l'écart tra immagine e parola. Il mezzo meccanico (la cinepresa) lo diverte soprattutto per il suo lato optique, spesso sconfinante nell'erotico e che, nelle sue incursioni, mantiene sempre lo stesso aspetto ludico delle opere pittoriche. Tout se tient, ovvero ogni creazione duchampiana si collega alle precedenti, esattamente come in un cerchio. I collanti essenziali si ripetono: ironia, erotismo, rivoluzione. L'influenza di questa creazione è descritta nell'ultima parte, «Duchamp un héritage cinématographique?», e trova la maggiore espressione nel cinema sperimentale degli anni Sessanta (in particolare Truffaut) in quanto legato all'idea di film ready-made, basato sul montaggio. Il cinema diventa quindi materia d'immagine informe e di passaggio, che travalica ogni categorizzazione. 